\title{
Tratamentos Térmico e Químico de Sementes de Feijoeiro: Eficiência na Erradicação de Curtobacterium flaccumfaciens pv. flaccumfaciens e Efeitos na Qualidade Fisiológica das Sementes
}

\author{
Renata C.C. Estefani, Reinaldo J. Miranda Filho \& Carlos H. Uesugi \\ Departamento de Fitopatologia, Universidade de Brasília, CEP 70910-900, Brasília, DF, Brasil, e-mail: uesugich@unb.br
} Autor para correspondência: Carlos H. Uesugi

ESTEFANI, R.C.C., MIRANDA FILHO, R.J. \& UESUGI, C.H. Tratamentos térmico e químico de sementes de feijoeiro: eficiência na erradicação de Curtobacterium flaccumfaciens pv. flaccumfaciens e efeitos na qualidade fisiológica das sementes. Fitopatologia Brasileira 32:434-438. 2007.

\section{RESUMO}

Foram testados o efeito da termo e quimioterapia na erradicação de Curtobacterium flaccumfaciens pv. flaccumfaciens (Cff) e sobre a qualidade fisiológica de sementes de feijoeiro (Phaseolus vulgaris) cv. Pérola. Os tempos (30 min, 1 e 2 h) de embebição em água e em soluções de AGRIMAICIN 500 (sulfato de cobre, $500 \mathrm{~g}+$ oxitetraciclina, $30 \mathrm{~g} / \mathrm{kg}$ do produto) nas concentrações de 5 e $10 \mathrm{~g} / \mathrm{L}$ de água; o calor seco $\left(60\right.$ e $70{ }^{\circ} \mathrm{C}$ por $1,2,3,6$ e $12 \mathrm{~h}$ ); e calor a $60{ }^{\circ} \mathrm{C} / 3 \mathrm{~h}$ em sementes previamente embebidas em água por $30 \mathrm{~min}, 1$ e $2 \mathrm{~h}$ foram aplicados. Sementes embebidas em água por mais de $1 \mathrm{~h}$ tiveram o vigor afetado. Embebição das sementes (30 min, 1 e 2 h) em solução com 10 g de AGRIMAICIN 500/L de água afetou o comprimento das radículas e dos caulículos, enquanto que a germinação só foi afetada com $2 \mathrm{~h}$. O tratamento eliminou a bactéria de sementes naturalmente infectadas, no entanto, em sementes inoculadas $\left(10^{8} \mathrm{ufc} / \mathrm{mL}\right)$ o tratamento não foi efetivo. Exposição ao calor seco $\left(60\right.$ e $\left.70^{\circ} \mathrm{C}\right)$ por mais de $3 \mathrm{~h}$ reduziu significativamente o vigor das sementes, mas não eliminou a bactéria. Embebição das sementes em água por $30 \mathrm{~min} \mathrm{e} 1 \mathrm{~h}+60^{\circ} \mathrm{C} / 3 \mathrm{~h}$ afetou o comprimento dos caulículos e das radículas, mas não eliminou a bactéria. Embebição das sementes por duas horas em água $+60^{\circ} \mathrm{C} / 3 \mathrm{~h}$ reduziu significativamente a germinação e o vigor; reduziu, ainda, significativamente o número de células de Cff em sementes inoculadas e eliminou a bactéria em sementes naturalmente infectadas.

Palavras-chave adicionais: Phaseolus vulgaris, murcha-de-Curtobacterium, controle, antibiótico, cúpricos.

\begin{abstract}
Thermal and chemical treatments of common bean seeds: Efficiency in Curtobacterium flaccumfaciens pv. flaccumfaciens eradication and effects on the physiological quality of seeds

The effect of thermo and chemotherapy on the eradication of Curtobacterium flaccumfaciens pv. flaccumfaciens (Cff) and on the physiological quality of seeds of common bean (Phaseolus vulgaris) cv. Pérola were tested. Soaking times ( $30 \mathrm{~min}, 1$ and $2 \mathrm{~h}$ ) in water and in AGRIMAICIN 500 solutions (copper sulphate, $500 \mathrm{~g}+$ oxytetracyclin, $30 \mathrm{~g} / \mathrm{kg}$ of the product) in concentrations of 5 and $10 \mathrm{~g} / \mathrm{L}$ of water; dry heat $\left(60\right.$ and $70{ }^{\circ} \mathrm{C}$ for $1,2,3,6$ and $\left.12 \mathrm{~h}\right)$; and heat of $60{ }^{\circ} \mathrm{C} / 3 \mathrm{~h}$ on previously soaked seeds for $30 \mathrm{~min}, 1$ and $2 \mathrm{~h}$ were tested. The vigor of seeds soaked in water for more than $1 \mathrm{~h}$ was affected. Soaking the seeds ( $30 \mathrm{~min}, 1$ and $2 \mathrm{~h}$ ) in solution with $10 \mathrm{~g}$ of AGRIMAICIN 500/L of water affected the length of the rootlet and the stem, whereas germination was affected only with $2 \mathrm{~h}$. The treatment eliminated the bacterium from naturally infected seeds; however it was not effective in inoculated seeds $\left(10^{8} \mathrm{ufc} / \mathrm{mL}\right)$. Dry heat $\left(60\right.$ and $\left.70{ }^{\circ} \mathrm{C}\right)$ for more than $3 \mathrm{~h}$ reduced significantly the vigor of the seeds and did not eliminate the bacterium. Soaking the seeds for $30 \mathrm{~min}$ and 1 $\mathrm{h}+60^{\circ} \mathrm{C} / 3 \mathrm{~h}$ affected the length of the stem and rootlet but did not eliminate the bacterium. Two hours of soaking the seeds in water $\pm 60{ }^{\circ} \mathrm{C} / 3 \mathrm{~h}$ reduced significantly the germination and the vigor; it also reduced significantly the Cff in inoculated seeds, whereas it eliminated the bacterium in naturally infected ones.
\end{abstract}

Additional keywords: Phaseolus vulgaris, curtobacterium wilt, control, antibiotic, copper.

A maioria das culturas destinadas à produção de alimentos está sujeita a doenças, sendo grande parte dos seus agentes etiológicos transmitidos por sementes. No caso específico do feijoeiro (Phaseolus vulgaris L.), mais de $50 \%$ das suas principais enfermidades têm seus

Parte do trabalho de Dissertação de Mestrado do primeiro autor. Universidade de Brasília. Brasília DF. 2004. agentes causais transmitidos via sementes (Neergaard, 1979). Além disso, existe uma tradição do uso de sementes próprias, que é um dos grandes entraves ao incremento da produtividade (Yokoyama et al., 2000). A má qualidade das sementes representa uma das principais causas da baixa produtividade em lavouras de feijoeiro no Brasil, pois as sementes costumeiramente utilizadas pelos agricultores geralmente apresentam graus variáveis de mistura, alto grau de umidade, germinação e vigor baixos, além de estarem infestadas por insetos, principalmente, pela presença de 
patógenos (Menten, 1978).

A cultura do feijoeiro comum é afetada por vários tipos de patógenos causadores de doenças as quais podem ser de origem fúngica, virótica e bacteriana que acarretam perdas significativas na produção. A murcha-deCurtobacterium, causada por Curtobacterium flaccumfaciens pv. Alaccumfaciens (Hedges) Collins \& Jones (Cff), foi inicialmente relatada nos Estados Unidos da América, em Dakota do Sul, por Hedges em 1922. Posteriormente, foi detectada em outras localidades norte-americanas (Venette et al., 1995) e em alguns países europeus, ocorrendo também na Austrália, Canadá, México e Colômbia (COSAVE, 2003). Desde o seu surgimento, em 1922, a Cff foi considerada um dos patógenos mais importantes dos feijoeiros do gênero Phaseolus, causando perdas totais em alguns anos (COSAVE, 2003). A identificação de Cff no Brasil é muito recente, sendo detectada no Estado de São Paulo no final da década de 90 por Maringoni \& Rosa (1997). Mais recentemente, Uesugi et al. (2003) relataram a ocorrência da bactéria no Distrito Federal e no Estado de Goiás.

A bactéria caracteriza-se por ser uma parasita vascular que infecta as plantas a partir de sementes contaminadas, ferimentos ou aberturas naturais e pode sobreviver em partes mortas da planta, no solo e em sementes (Saettler, 1991). Entre os métodos de tratamento de sementes descritos na literatura, a termoterapia é um dos mais citados para erradicação de fitobactérias localizadas interna ou externamente nas sementes. A termoterapia pode ser aplicada via calor úmido (água quente ou vapor) ou calor seco. O calor seco apresenta menor capacidade térmica ou troca de calor que a via úmida, requerendo, portanto, maior tempo de exposição. Entretanto, é mais simples e mais acessível, além de causar menos danos às sementes, já que não há o rompimento do tegumento e/ ou extravasamento de substâncias das sementes, comum na embebição em água quente e vapor arejado (Menten, 1995). A faixa de temperatura e os períodos de exposição a serem aplicados às sementes variam conforme a espécie hospedeira e a sua sensibilidade ao calor. A sensibilidade das células bacterianas ao calor pode variar com a idade da cultura ou das células bacterianas e até a própria origem geográfica do isolado, que pode apresentar diferenças genéticas (Grondeau \& Samson, 1994).

O presente trabalho objetivou testar os tratamentos térmico e químico na erradicação de $C$. flaccumfaciens pv. flaccumfaciens e sobre a qualidade fisiológica de sementes de feijoeiro. Os experimentos foram conduzidos no Laboratório de Fitopatologia da Universidade de Brasília, situado no Campus Darcy Ribeiro, Brasília DF.

Para testar o tempo de embebição das sementes de feijoeiro da cultivar Pérola em água e em solução de AGRIMAICIN 500 (formulação com $500 \mathrm{~g}$ de sulfato de cobre $+30 \mathrm{~g}$ de oxitetraciclina $/ \mathrm{kg}$ ) sobre a qualidade fisiológica, as sementes sadias foram submetidas aos seguintes tratamentos: embebição (30 min, 1 e 2 h) em água destilada $\left( \pm 25^{\circ} \mathrm{C}\right)$ e em soluções de AGRIMAICIN 500 $\left( \pm 25^{\circ} \mathrm{C}\right)$ nas concentrações de 5 e $10 \mathrm{~g} / \mathrm{L}$ de água. Depois da embebição, as sementes foram distribuídas em Gerbox, entre papéis-toalha umedecidos, e colocadas em câmara para germinação, $\pm 25^{\circ} \mathrm{C} / 12 \mathrm{~h}$ de luz. A avaliação foi feita quatro dias após a instalação dos experimentos, onde se mediu o percentual de germinação e o comprimento das radículas e dos caulículos, segundo Carvalho \& Nakagawa (2000). $\mathrm{O}$ experimento constou de um fatorial $3 \times 2$. As médias foram comparadas pelo teste de Tukey ao nível de $5 \%$ de probabilidade.

Influência da termoterapia na qualidade fisiológica das sementes sem (calor seco) e com embebição em água. Dois experimentos com sementes livres do patógeno foram conduzidos em uma estufa BIOMATIC. O primeiro (calor seco) constou de 10 tratamentos (temperaturas de $60 \mathrm{e}$ $70{ }^{\circ} \mathrm{C}$ por $1,2,3,6$ e $12 \mathrm{~h}$ ), três repetições e 50 sementes por tratamento. $\mathrm{O}$ segundo, sementes embebidas em água, conforme descrito anteriormente, foram submetidas à $60{ }^{\circ} \mathrm{C} / 3 \mathrm{~h}$. As condições para germinação e a avaliação foram as mesmas descritas anteriormente. $\mathrm{O}$ delineamento experimental foi inteiramente casualizado com três repetições de 50 sementes. Os dados foram analisados e a diferença entre as médias verificada conforme mencionado acima.

Erradicação da Cff com AGRIMAICIN 500 e termoterapia. Dez sementes da cv. Pérola, colhidas de um campo comercial com alta incidência de murchade-Curtobacterium, no município de Cristalina, Goiás, foram utilizadas por tratamento. Os tratamentos com AGRIMAICIN 500 e a termoterapia de sementes sem e com embebição em água foram conforme descrito anteriormente. Após os tratamentos as sementes foram trituradas com o auxílio de um almofariz. Ao triturado foram acrescentados $20 \mathrm{~mL}$ de água destilada esterilizada $\left( \pm 25^{\circ} \mathrm{C}\right)$ e, após a homogeneização, alíquotas de $50 \mu \mathrm{L}$ da suspensão foram plaqueadas em meio 523 de Kado \& Heskett (1970) com três repetições por tratamento. As placas foram incubadas a $28^{\circ} \mathrm{C}$ e a avaliação feita quatro dias após a instalação dos ensaios, observando-se o crescimento de colônias de Cff.

Tratamentos térmico e químico de sementes inoculadas. Cem sementes da cultivar Pérola, livres do patógeno, foram desinfestadas [álcool $70 \%$ (30 s), hipoclorito de sódio $1 \%(10 \mathrm{~min})$, lavadas com água destilada esterilizada], embebidas por $30 \mathrm{~min}$ em $200 \mathrm{~mL}$ de suspensão $\left( \pm 25{ }^{\circ} \mathrm{C}\right)$ de células de $\mathrm{Cff}\left(10^{8} \mathrm{ufc} / \mathrm{mL}\right)$ e secas em temperatura ambiente $\left( \pm 25^{\circ} \mathrm{C}\right)$ por $48 \mathrm{~h}$. Na termoterapia, as sementes inoculadas foram embebidas em água $\left( \pm 25^{\circ} \mathrm{C}\right)$ por $2 \mathrm{~h} \mathrm{e}$, em seguida, mantidas em estufa por $3 \mathrm{~h}$ a $60^{\circ} \mathrm{C}$, enquanto que na quimioterapia, as sementes foram embebidas por $2 \mathrm{~h}$ em solução contendo 10 g de AGRIMAICIN 500/L de água $\left( \pm 25^{\circ} \mathrm{C}\right)$. A extração e a incubação foram conforme descrito anteriormente. O experimento constou de três tratamentos de 20 sementes, quatro repetições e três placas por repetição. Após quatro dias contouse o número de colônias por placa. A embebição das sementes em água entre 30 min e $2 \mathrm{~h}$ não afetou a germinação, enquanto mais de $1 \mathrm{~h}$ afetou tanto o comprimento dos caulículos como o 
TABELA 1 - Qualidade fisiológica das sementes de feijoeiro (Phaseolus vulgaris) cultivar Pérola e presença de Curtobacterium flaccumfaciens pv. flaccumfaciens (Cff) sob diferentes tratamentos

\begin{tabular}{|c|c|c|c|c|c|}
\hline \multicolumn{2}{|c|}{ Tratamentos } & \multirow{2}{*}{$\begin{array}{c}\text { Germinação } \\
(\%)\end{array}$} & \multirow{2}{*}{$\begin{array}{c}\mathrm{CP} \\
(\mathrm{cm})\end{array}$} & \multirow{2}{*}{$\begin{array}{c}\mathrm{CC} \\
(\mathrm{cm})\end{array}$} & \multirow{2}{*}{$\begin{array}{c}\text { Presença } \\
\text { de Cff }\end{array}$} \\
\hline $\begin{array}{l}\text { Embebição em água ou solução de } \\
\text { AGRIMAICIN } 500 \text { (min) }\end{array}$ & $\begin{array}{c}\text { Concentração de AGRIMAICIN } \\
500 \text { (g/L de água) }\end{array}$ & & & & \\
\hline 0 (Testemunha ) & 0 & $100 \mathrm{a}$ & $7,7 \mathrm{a}$ & $7,3 \mathrm{a}$ & ND \\
\hline 30 & 0 & $100 \mathrm{a}$ & $8,2 \mathrm{a}$ & $7,7 \mathrm{a}$ & ND \\
\hline 60 & 0 & $98 \mathrm{ab}$ & $5,7 \mathrm{~b}$ & $5,9 \mathrm{~b}$ & ND \\
\hline 120 & 0 & $92 \mathrm{ab}$ & $3,7 \mathrm{c}$ & $3,9 \mathrm{~d}$ & ND \\
\hline 30 & 5 & $100 \mathrm{a}$ & $3,4 \mathrm{c}$ & $4,22 \mathrm{~cd}$ & + \\
\hline 60 & 5 & $95,3 \mathrm{ab}$ & $3,5 \mathrm{c}$ & $4,9 \mathrm{bc}$ & + \\
\hline 120 & 5 & $92,6 \mathrm{ab}$ & $3,6 \mathrm{c}$ & $4,3 \mathrm{~cd}$ & + \\
\hline 30 & 10 & $93,3 \mathrm{ab}$ & $3,3 \mathrm{c}$ & $4,3 \mathrm{~cd}$ & Zero \\
\hline 60 & 10 & $91,3 \mathrm{~b}$ & $3,6 \mathrm{c}$ & $4,5 \mathrm{~cd}$ & Zero \\
\hline 120 & 10 & $81,33 \mathrm{c}$ & $3,4 \mathrm{c}$ & $3,5 \mathrm{~d}$ & Zero \\
\hline \multicolumn{2}{|c|}{ C.V. $(\%)$} & 6,5 & 55,5 & 55,6 & - \\
\hline
\end{tabular}

Médias seguidas da mesma letra não diferem entre si pelo teste de Tukey ao nível de 5\% de probabilidade; CR (comprimento da radícula) e CC (comprimento do caulículo) 4 dias após tratamento; AGRIMAICIN $500^{\circledR}$ (sulfato de cobre, $500 \mathrm{~g}+$ oxitetraciclina, $30 \mathrm{~g} / \mathrm{kg}$ do produto), marca registrada do Laboratórios Pfizer; ND - Não determinado.

das radículas (Tabela 1 ).

A concentração e o tempo de embebição das sementes em solução de AGRIMAICIN 500 influenciaram no vigor das sementes. Embebição em solução com $10 \mathrm{~g}$ do produto/L de água por 1 e $2 \mathrm{~h}$ reduziu significativamente a germinação quando comparada com a testemunha; a embebição em água e a embebição em solução com $5 \mathrm{~g}$ do produto/L de água por 30 min. Já a embebição das sementes por 30 min e $1 \mathrm{~h}$ nas concentrações de 5 e $10 \mathrm{~g}$ do produto/L de água afetou significativamente o comprimento dos caulículos e das radículas, quando comparadas com as embebidas em água, não havendo, porém, diferenças entre as concentrações (Tabela 1). Nas sementes embebidas por $30 \mathrm{~min}, 1 \mathrm{e} 2 \mathrm{~h}$ em solução de AGRIMAICIN 500 na concentração de $5 \mathrm{~g} / \mathrm{L}$ de água foi possível recuperar a Cff. Não houve crescimento da Cff em nenhum dos três tempos de embebição das sementes quando a concentração do produto foi de $10 \mathrm{~g} / \mathrm{L}$ de água (Tabela 1).

Exposição das sementes ao calor seco a 60 e $70^{\circ} \mathrm{C}$ por mais de $3 \mathrm{~h}$ reduziu significativamente o desenvolvimento das plântulas e não eliminou a bactéria (dados não apresentados). Em sementes previamente embebidas em água $\left(30 \mathrm{~min}, 1 \mathrm{e} 2 \mathrm{~h}\right.$ ) e posterior tratamento a $60^{\circ} \mathrm{C} / 3 \mathrm{~h}$, praticamente não houve diferença significativa no percentual de germinação, excetuando o de $2 \mathrm{~h}$, que foi menor, sendo este estatisticamente igual ao de $2 \mathrm{~h}$ de embebição em água (Tabela 2). Resultados semelhantes foram obtidos por Belletti \& Tamietti (1982), que observaram que a embebição das sementes por $2 \mathrm{~h}$ e 30 min mais tratamento térmico a 60 ${ }^{\circ} \mathrm{C} / 3 \mathrm{~h}$ reduziu significativamente a germinação de sementes de feijoeiro $\mathrm{O}$ tratamento de $2 \mathrm{~h}$ de embebição em água e exposição a $60{ }^{\circ} \mathrm{C} / 3 \mathrm{~h}$ foi significativamente inferior aos demais (Tabela 2).

Segundo Machado (2000), a termoterapia é mais danosa ao vigor à medida que a semente apresenta qualidade fisiológica inferior. Sementes mais vigorosas são mais tolerantes a temperaturas mais altas do que as sementes com vigor comprometido. De fato, durante a avaliação dos experimentos observou-se que algumas plântulas oriundas de sementes submetidas ao mesmo tratamento apresentavam um comportamento muito diferente com relação ao crescimento, sendo muito maiores, enquanto outras mostravam defeitos tanto na radícula quanto no caulículo.

Embebição de sementes com infecção natural por 30 min e $1 \mathrm{~h}+60^{\circ} \mathrm{C}$ por $3 \mathrm{~h}$ não foram efetivos na erradicação da Cff, já o mesmo tratamento mas com $2 \mathrm{~h}$ de embebição resultou na eliminação do patógeno (Tabela 2).

Em sementes inoculadas, naquelas embebidas em solução com $10 \mathrm{~g}$ de AGRIMAICIN 500/L de água por $2 \mathrm{~h}$, não reduziu significativamente a concentração de Cff quando comparada com a testemunha, enquanto que nas tratadas com $2 \mathrm{~h}$ de embebição em água $+60^{\circ} \mathrm{C} / 3 \mathrm{~h}$ a redução foi significativa, tanto em relação à testemunha quanto ao tratamento químico (Tabela 3).

A termoterapia reduziu em $90 \%$ a quantidade de células bacterianas nas sementes inoculadas, sendo que esta redução observada na quantidade do inóculo constitui-se num resultado desejável. Já no controle químico, observouse que a embebição em solução com $10 \mathrm{~g}$ de AGRIMAICIN $500 / \mathrm{L}$ de água por $2 \mathrm{~h}$ não foi efetivo na erradicação de Cff. 
TABELA 2 - Qualidade fisiológica das sementes de feijoeiro (Phaseolus vulgaris) cultivar Pérola e presença de Curtobacterium flaccumfaciens pv. flaccumfaciens (Cff) sob diferentes períodos de embebição e tratamento térmico

\begin{tabular}{|c|c|c|c|c|c|}
\hline \multicolumn{2}{|l|}{ Tratamentos } & \multirow{2}{*}{$\begin{array}{c}\text { Germinação } \\
(\%)\end{array}$} & \multirow{2}{*}{$\begin{array}{c}\text { CR } \\
\text { (cm) }\end{array}$} & \multirow{2}{*}{$\begin{array}{c}\mathrm{CC} \\
(\mathrm{cm})\end{array}$} & \multirow{2}{*}{$\begin{array}{c}\text { Presença de } \\
\text { Cff }\end{array}$} \\
\hline Embebição em água (min) & $\begin{array}{c}60{ }^{\circ} \mathrm{C} / \\
3 \mathrm{~h} \\
\end{array}$ & & & & \\
\hline 0 (Testemunha) & - & $100 \mathrm{a}$ & $7,7 \mathrm{a}$ & $7,3 \mathrm{a}$ & ND \\
\hline 30 & - & $100 \mathrm{a}$ & $8,4 \mathrm{a}$ & $6,9 \mathrm{a}$ & ND \\
\hline 60 & - & $97 \mathrm{a}$ & $7,6 \mathrm{a}$ & $5,1 \mathrm{~b}$ & ND \\
\hline 120 & - & $83 \mathrm{ab}$ & $4,2 \mathrm{~cd}$ & $2,8 \mathrm{de}$ & ND \\
\hline 30 & + & $91 \mathrm{a}$ & $5,9 \mathrm{~b}$ & $3,8 \mathrm{c}$ & + \\
\hline 60 & + & $94 \mathrm{a}$ & $5,2 \mathrm{bc}$ & $3,4 \mathrm{~cd}$ & + \\
\hline 120 & + & $69 \mathrm{~b}$ & $3,4 \mathrm{~d}$ & $2,2 \mathrm{e}$ & Zero \\
\hline C.V. $(\%)$ & & 7,5 & 50,8 & 56,5 & \\
\hline
\end{tabular}

Médias seguidas da mesma letra não diferem entre si pelo teste de Tukey ao nível de $5 \%$ de probabilidade; CR (comprimento da radícula) e CC (comprimento do caulículo) 4 dias após tratamento. ND - Não determinado.

Este fato pode estar relacionado com a baixa eficiência do produto quando a concentração da bactéria por semente é muito alta, visto que, em sementes naturalmente infectadas, possivelmente com menor concentração de Cff, foi possível eliminá-la. Outra possibilidade seria a ineficácia do método utilizado no tratamento das sementes.

Os resultados do presente trabalho indicaram boas perspectivas de utilização do tratamento térmico na erradicação de Cff em sementes de feijoeiro. Do ponto de vista ambiental, é um método não poluente ou sem efeito

TABELA 3 - Quantidade de células bacterianas presentes em sementes de feijoeiro (Phaseolus vulgaris) cultivar Pérola, inoculadas com Curtobacterium flaccumfaciens pv. flaccumfaciens e submetidas aos tratamentos térmico e químico

\begin{tabular}{|c|c|c|}
\hline Tratamento & $u f c / m L x 10^{4}$ & $\begin{array}{r}20 \text { sementes } \\
\left(\text { ufc } \times 10^{5}\right)\end{array}$ \\
\hline Testemunha & $1,42 \mathrm{a}$ & $2,85 \mathrm{a}$ \\
\hline Químico & $1,10 \mathrm{a}$ & $2,20 \mathrm{a}$ \\
\hline Térmico & $0,14 \mathrm{~b}$ & $0,28 \mathrm{~b}$ \\
\hline C.V. & 17,7 & 8,4 \\
\hline \multicolumn{3}{|c|}{$\begin{array}{l}\text { Médias seguidas da mesma letra não diferem entre si } \\
\text { pelo teste de Tukey ao nível de } 5 \% \text { de probabilidade. } \\
\text { Testemunha }- \text { Sementes inoculadas (conc. } 1 \mathrm{x} \\
10^{8} \text { ufc } / \mathrm{mL} \text { ) sem tratamento térmico ou químico; } \\
\text { Químico - Sementes inoculadas embebidas por } 2 \mathrm{~h} \\
\text { em solução de AGRIMAICIN } 500 \text { (sulfato de cobre, } \\
500 \mathrm{~g}+\text { oxitetraciclina, } 30 \mathrm{~g} / \mathrm{kg} \text { do produto) } 10 \mathrm{~g} / \mathrm{L} \text {; } \\
\text { Térmico - Sementes inoculadas embebidas por } 2 \mathrm{~h} \text {. } \\
\text { em água e tratadas a } 60^{\circ} \mathrm{C} / 3 \mathrm{~h} \text {. AGRIMAICIN } 500^{\circledR} \text {, } \\
\text { marca registrada do Laboratórios Pfizer. }\end{array}$} \\
\hline
\end{tabular}

residual e deve ser recomendado para erradicação de patógenos. Porém, a termoterapia apresenta inconveniente de não ser simples quando aplicada a grandes quantidades de sementes para plantio. Portanto, serão necessários mais estudos para a viabilização do emprego deste método em lavouras comerciais.

\section{AGRADECIMENTOS}

O primeiro autor agradece ao Conselho Nacional de Desenvolvimento Científico e Tecnológico - CNPq pela concessão de bolsa de estudo.

\section{REFERÊNCIAS BIBLIOGRÁFICAS}

BELLETTI, P. \& TAMIETTI, G. L'impiego del calore secco nel risanamento dei semi di fagiolo infetti da Pseudomonas phaseolicola. Informatore Fitopatologico 33:59-61. 1982.

CARVALHO, N.M. \& NAKAGAWA, J. Sementes: ciência, tecnologia e produção. 4. Ed. Jaboticabal SP. Funep. 2000.

COSAVE - COMITE DE SANIDADE VEGETAL DEL CONO SUR. Plagas Cuarentenarias: Curtobacterium flaccumfaciens pv. flaccumfaciens. http://www.cosave.org.py, 2003.

GRONDEAU, C. \& SAMSON, R. A review of thermotherapy to free plant materials from pathogens, especially seeds from bacteria. Critical Reviews in Plant Sciences 13:57-75. 1994.

HEDGES, F. A bacterial wilt of the bean caused by Bacterium flaccumfaciens nov. sp. Science 55:433-434.1922.

KADO, C.I. \& HESKETT, M.G. Selective media for isolation of Agrobacterium, Corynebacterium, Erwinia, Pseudomonas and Xanthomonas. Phytopathology 60:969-979. 1970. 
MACHADO, J.C. Tratamento de sementes no controle de doenças. Lavras MG. Apostila. UFLA, FAEPE. 2000.

MARINGONI, A.C. \& ROSA, E.F. Ocorrência de Curtobacterium flaccumfaciens pv. flaccumfaciens em feijoeiro no Estado de São Paulo. Summa Phytopathologica 23:160-162. 1997.

MENTEN, J.O.M. Sanidade, germinação e vigor das sementes de feijão (Phaseolus vulgaris L.). Summa Phytopathologica 4:105110. 1978.

MENTEN, J.O.M. Patógenos em sementes, detecção, danos e controle químico. São Paulo. Ciba Agro. 1995.

NEERGAARD, P. Seed Pathology. London. Mac Millan Press. 1979.

SAETTLER, A.W. Diseases caused by bacteria. In: Hall, R. (Ed.)
Compendium of bean diseases. Saint Paul MN. APS Press. 1991. pp. 29-32.

UESUGI, C.H., FREITAS, M.A. \& MENEZES, J.R. Ocorrência de Curtobacterium flaccumfaciens pv. flaccumfaciens em feijoeiro, em Goiás e no Distrito Federal. Fitopatologia Brasileira 28:324. 2003.

VENETTE, J.R., LAMPRA, R.S. \& GROSS, P.L. First report of bean bacterial wilt caused by Curtobacterium flaccumfaciens pv. flaccumfaciens in North Dakota. Plant Disease 79:966. 1995.

YOKOYAMA, L.P., WETZEL, C.T., VIEIRA, E.H.N. \& PEREIRA, G.V. Sementes de Feijão: produção, uso e comercialização. In: Vieira, E.H.N. \& Rava, C.A. (Eds.) Sementes de Feijão: produção e tecnologia. Santo Antônio de Goiás GO. Embrapa Arroz e Feijão. 2000. pp. 249-270. 